\title{
CARTILHA ILUSTRADA COM ALGUNS ANIMAIS NATIVOS DO CERRADO: um material paradidático de ciências, para estudantes de escolas públicas de Esmeraldas - MG
}

Fernanda Medeiros DINIZ ${ }^{1}$

Dirceu Antônio CORDEIRO JÚNIOR ${ }^{2}$

Claudia de Vilhena Schayer SABINO ${ }^{3}$

\begin{abstract}
${ }^{1}$ Mestre em Ensino de Ciências e Matemática. Docente da Escola Estadual Santa Quitéria. fernandamedeirosdiniz@yahoo.com.br

${ }^{2}$ Doutor em Biologia Celular. Docente do curso de Odontologia da Universidade Vale do Rio Verde - UninCor, campus Belo Horizonte. prof.dirceu.cordeiro@unincor.edu.br

${ }^{3}$ Doutora em Química. Docente do Mestrado em Ensino de Ciências e Matemática da Pontifícia Universidade Católica de Minas Gerais- PUC MINAS - campus Belo Horizonte. sabinoc@pucminas.br
\end{abstract}

Recebido em: 19/09/2016 - Aprovado em: 17/122016 - Disponibilizado em: 18/12/2016

\section{RESUMO:}

A carência de informações sobre a fauna nativa é uma característica marcante nos livros didáticos de ciências adotados pela rede pública do Brasil. A falta de materiais didáticos e paradidáticos contextualizados cria uma lacuna e uma fragmentação do conhecimento dos alunos nas escolas públicas. Buscamos fornecer subsídios para melhorar alguns aspectos do ensino de ciências na rede pública através da produção e da utilização de uma cartilha ilustrada com alguns animais nativos do Cerrado, inserindo assim um tema fundamental para a valorização e a proteção ambiental.Esse material foi distribuído em duas escolas públicas estaduais, levando em consideração a realidade de cada escola. Para a elaboração da cartilha, procuramos conhecer as concepções dos estudantes, analisando questionários relativos aos animais nativos, bem como as concepções de professores, através de entrevistas que objetivavam verificar a abordagem do tema "fauna nativa" nos livros didáticos de $6^{\circ}$ e $7^{\circ}$ anos finais do ensino fundamental. Após a utilização do material proposto, verificou-se um melhor entendimento sobre a biodiversidade nativa do Cerrado e um aumento perceptível nas citações de animais nativos nos questionários aplicados aos estudantes.

Palavras-chave: materiais paradidáticos, livro didático, fauna nativa, Cerrado, animais silvestres, ensino fundamental.

\section{ILLUSTRATED GUIDEBOOK WITH SOME WILD ANIMALS OF THE CERRADO: a paradidactic material of sciences, for students of public schools of Esmeraldas - MG}

\begin{abstract}
:
The scarcity of information about the fauna of Brazil is a strong feature of the didactic books utilized in Brazilian public schools. The lack of contextualized didactic and paradidactic materials generates a knowledge gap and a fragmentation in the educational background of Brazilian children studying in public schools. By means of the production of an illustrated syllabus comprising some animals from the Cerrado region of Brazil, we aimed to improve some aspects of the public educational system, encouraging students to respect and preserve the global environment. This syllabus was sent to two state schools, taking in account the overall aspects of each school. Prior to syllabus preparation, we tried to be acquainted with the views of students and teachers, by performing interviews and surveys related to wild animals and how the fauna of Brazil is discussed in the didactic books of $6^{\text {th }}$ and $7^{\text {th }}$ grades of elementary school. Once the syllabus was applied in the Science classes of these two schools, we noted that students improved their understanding about the biodiversity of the Cerrado region and were able to mention more wild animals in the surveys applied afterwards .Keywords: paradidactic materials, didactic books, native fauna, Cerrado, wild animals, elementary school
\end{abstract}




\section{INTRODUÇÃO}

A carência de informações sobre a fauna brasileira é uma característica marcante nos livros didáticos de ciências adotados pela rede pública do Brasil (GUERRA; GUSMÃO, 2000). Segundo Guerra (2002), a falta de materiais didáticos e paradidáticos contextualizados cria uma lacuna e uma fragmentação do conhecimento dos alunos nas escolas públicas. Grande parte dos estudantes do ensino fundamental tem o livro didático como uma das principais fontes de informação. A pouca valorização das espécies nativas nesse tipo de material acaba por e constituir um importante fator com reflexos negativos na biologia da conservação.O livro instrui, informa, diverte, mas acima de tudo prepara para a liberdade. Em conjunto com outras ferramentas, o livro didático tem-se mostrado um dos mais perenes instrumentos de ensino. Isso se deve, em parte, à versatilidade dos materiais editados e à relativa facilidade de acesso, proporcionada pelas políticas públicascomo o Programa Nacional do Livro Didático - PNLD (BRASIL, 2010).

A pesquisa foi desenvolvida no município de Esmeraldas, MG, que possui paisagens variadas constituídas predominantemente pelo bioma Cerrado e suas variações. Um grande problema identificado nessa cidade é a ocupação desordenada da população, que tem provocado a degradação de áreas importantes (RODRIGUES, 2000). Segundo os dados do IBGE relativos ao censo realizado em 1996 e divulgados por Rodrigues (2000), Esmeraldas foi o município que obteve o maior índice de crescimento populacional, vítima do fenômeno denominado "metropolização", causado pelo êxodo urbano dos grandes centros de sua vizinhança (como Belo Horizonte, Contagem, Betim, Sete Lagoas e Ribeirão das Neves). Foi também vítima de invasões em locais sem infraestrutura, como nas chamadas "áreas verdes" (COSTA et al., 2006). De acordo com esses dados, em 1996 existiam 34.000 habitantes em Esmeraldas; em 2014 esse número é superior a 66.000 (IBGE, 2014).

A proposta da pesquisa aqui apresentada foi construir uma cartilha ilustrada com alguns animais do Cerrado, de forma a fornecer subsídios para melhorar alguns aspectos do ensino de ciências na rede pública, através da inserção de um tema fundamental para a valorização e a proteção ambiental. Para a elaboração desse material paradidático, investigamos as concepções dos estudantes e professores de escolas públicas estaduais, em relação aos animais nativos e à degradação ambiental. Também verificamos como o tema "fauna nativa" é abordado nos livros didáticos de $6^{\circ}$ e $7^{\circ}$ anos do ensino fundamental, verificando a apresentação desse aspecto nos conteúdos do currículo. 


\section{METODOLOGIA}

\section{As escolas}

A pesquisa aqui relatada foi desenvolvida nas escolas públicas e estaduais centrais da cidade de Esmeraldas, região metropolitana de Belo Horizonte: Escola Estadual Santa Quitéria e Escola Estadual Professor Augusto Lucas. A Escola Estadual Santa Quitéria possui ensino médio durante os turnos da manhã, tarde e noite, e ensino fundamental durante o período da tarde. A Escola Estadual Professor Augusto Lucas possui ensino fundamental no turno da manhã e tarde, e Educação de Jovens e Adultos (EJA) no período da noite.

\section{Método adotado e coleta de dados}

Os dados foram obtidos por intermédio de questionários aplicados aos alunos de $6^{\circ} \mathrm{e} 7^{\circ}$ anos do ensino fundamental das escolas estaduais envolvidas na pesquisa e através de entrevistas com os professores de ciências que lecionam nas mesmas escolas. Os alunos responderam a dois questionários, um antes da apresentação da cartilha e outro após a utilização do material paradidático.

$\mathrm{Na}$ primeira fase do trabalho, 80 alunos matriculados e frequentes no $6^{\circ}$ ano e 91 alunos do $7^{\circ}$ ano responderam aos questionários, perfazendo um total de 171 estudantes. $\mathrm{Na}$ segunda fase, a cartilha foi apresentada a 40 estudantes do $6^{\circ}$ anoe a 53 estudantes do $7^{\circ}$ ano que haviam respondido ao questionário da primeira fase, num total de
93 estudantes. Após uma semana, foi aplicado novo questionário a esses 93 alunos que haviam trabalhado com a cartilha. As entrevistas também foram realizadas com três professores de ciências, com o objetivo de conhecer os métodos utilizados para se trabalhar o tema "animais nativos", e também com o intuito de identificar o perfil dos professores dessa disciplina que trabalham na rede estadual. As entrevistas foram gravadas e depois transcritas.

\section{Análise das coleções adotadas pelas escolas envolvidas nesta pesquisa}

Foi feita a análise das coleções adotadas nos $6^{\circ}$ e $7^{\circ}$ anos do ensino fundamental, buscando conhecer e identificar como o tema relativo à fauna nativa é tratado no livro didático adotado. Em cada conteúdo do programa que abordava a fauna silvestre, buscamos a presença e a valorização de fotos ou imagens que ilustram o tema. Foram selecionadas para exame duas coleções de livros didáticos dos $6^{\circ}$ e $7^{\circ}$ anosdo ensino fundamental, avaliadas pelo PNLD - Plano nacional do livro didático em 2010. De acordo com os professores, para a escolha do livro didático a ser adotado nas escolas foi realizado um levantamento das prioridades dos alunos, da realidade da escola, das propostas do CBC- Currículo Básico Comum, do PCN- Parâmetros Curriculares Nacionais, e foi considerada a avaliação do material no PNDL. A escolha do material foi realizada 
pelas escolas da seguinte forma: primeiramente foi feita uma análise sistemática da listagem de títulos discutidos e avaliados pelo Ministério da Educação e Cultura- MEC, disponíveis no PNLD 2010 (BRASIL, 2010); posteriormente, foi feita a verificação da disponibilidade dos livros na biblioteca das escolas centrais da rede estadual de Esmeraldas.

O primeiro passo foi analisar as obras e identificar nos conteúdos dos livros as abordagens sobre a fauna nativa e a presença das imagens ilustrativas sobre a mesma, com o objetivo de identificar a presença e a adequação à realidade dos alunos do conteúdo científico abordado nos livros. Como referências para a análise foram utilizados os PCNs - Parâmetros Curriculares Nacionais e o PNLD, que é um dos maiores programas de livro didático do mundo (BITTENCOURT, 2004).

\section{Elaboração da cartilha ilustrada com} alguns animais nativos do Cerrado

A partir da análise dos dados referentes às entrevistas, aos questionários e à análise do conteúdo presente no livro didático, passamos para a fase da pesquisa que incluiu a construção de uma cartilha ilustrada com alguns animais nativos do Cerrado, e a posterior verificação da reação dos estudantes frente ao material paradidático elaborado.
Para a elaboração da cartilha, foram escolhidos animais do Cerrado, principalmente os encontrados em Esmeraldas ou os que se enquadram em categorias de ameaças. O sentido dessa cartilha é divulgar a importância da fauna do Cerrado entre os estudantes das escolas públicas estaduais de Esmeraldas, mostrando a necessidade de respeitar e valorizar o bioma em que vivemos.

As imagens para a elaboração da cartilha foram obtidas no site do Ministério do Meio Ambiente (MMA) e gentilmente cedidas pelos biólogos Antônio Linhares, Cinara Clemente, Dirceu Cordeiro, Fernanda M. Diniz e Ramon Palhares. As informações da cartilha foram adaptadas das seguintes fontes: MMA, CEMIG e IUCN.

\section{RESULTADOS E DISCUSSÃO}

\section{Perfil dos estudantes}

Os estudantes que participaram da pesquisa são moradores das regiões centrais e da periferia da cidade de Esmeraldas, que constitui um dos 34 municípios integrantes da região metropolitana de Belo Horizonte (RODRIGUES， 2000). São residentes principalmente de regiões ruraisnormalmente sítios, fazendas e chácaras, e consequentemente conhecem e convivem com o ambiente natural de pequenas cidades, reconhecidamente muito diferente do ambiente dos grandes centros urbanos. Em média, os alunos que participaram deste estudo possuem renda familiar igual ou 
inferior a um salário mínimo, e por esse motivo recebem a chamada bolsa escola ou bolsa família, que é um benefício oferecido pelo Governo Federal para as famílias carentes que apresentam atestado de pobreza. Poucos alunos entrevistados possuem computador ou tem acesso à internet.

\section{Perfil dos professores entrevistados}

Os professores que participaram desta pesquisa são docentes de ciências que lecionam em escolas públicas estaduais e municipais de Esmeraldas. São professores graduados, com licenciatura plena em Ciências Biológicas ou licenciatura em Ciências e Matemática. Todos são moradores da cidade e contratados com uma carga horária de 36 aulas semanais, sendo três aulas para cada turma. Cada um dos professores, portanto, trabalha com 12 turmas de ensino fundamental ou médio.

\section{Questionário aplicado aos estudantes de $6^{\circ} \mathrm{e}$}

\section{$7^{\circ}$ anos, na primeira fase da pesquisa}

Os questionários foram aplicados aos estudantes de $6^{\circ}$ e $7^{\circ}$ anosdo ensino fundamental, durante um momento da aula cedido pelo professor. Não houve abordagem do professor com os alunos sobre o tema, para não influenciar os resultados. As questões respondidas pelos alunos foram:

1. Você sabe a diferença entreanimais nativos e animais exóticos?

2. Cite os animais que você mais conhece.

3. Onde você aprendeu sobre esse animal? $\mathrm{Na}$ escola ou em outro meio? Qual?

4. O seu livro didático ilustra a fauna brasileira?

A tabela 1 registra as respostas obtidas para a primeira pergunta, em que os alunos são solicitados a responder se conhecem a diferença entre animais nativos e exóticos.

Tabela 1 - Respostas dos estudantes das Escolas Estaduais Santa Quitéria e Prof. Augusto Lucas, de Esmeraldas - MG, para a primeira pergunta: "Você sabe a diferença entre animais nativos e exóticos?"

\begin{tabular}{|c|c|c|c|}
\hline & Sim & Não & Total \\
\hline $\begin{array}{l}\text { Estudantes de } 5^{\text {a }} \text { série do ensino } \\
\text { fundamental da Escola Estadual Santa } \\
\text { Quitéria }\end{array}$ & 26 & 21 & 47 \\
\hline $\begin{array}{l}\text { Estudantes de } 5^{\text {a }} \text { série do ensino } \\
\text { fundamental da Escola Estadual Prof. } \\
\text { Augusto Lucas }\end{array}$ & 19 & 14 & 33 \\
\hline $\begin{array}{l}\text { Estudantes de } 6^{\text {a }} \text { série do ensino } \\
\text { fundamental da Escola Estadual Santa } \\
\text { Quitéria }\end{array}$ & 48 & 10 & 58 \\
\hline $\begin{array}{l}\text { Estudantes de } 6^{\mathrm{a}} \text { série do ensino } \\
\text { fundamental da Escola Estadual Prof. } \\
\text { Augusto Lucas }\end{array}$ & 13 & 20 & 33 \\
\hline Total & $\begin{array}{l}62 \% \\
(106)\end{array}$ & $\begin{array}{l}38 \% \\
(65) \\
\end{array}$ & (1 \\
\hline
\end{tabular}

Fonte: Questionário aplicado aos estudantes de $6^{\circ}$ e $7^{\circ}$ anos do ensino fundamental 
Embora a maioria dos estudantes tenha respondido que conhece a diferença entre animais nativos e exóticos, percebemos que não conseguem acertar a definição dos conceitos quando solicitados. Dos 80 estudantes do $6^{\circ}$ ano da E. E. Santa Quitéria e Prof. Augusto Lucas, nenhum conseguiu diferenciar os animais nativos dos animais exóticos. Dos 58 estudantes do $7^{\circ}$ ano da E. E Santa Quitéria, nove mostraram conhecer e diferenciar os termos. Já entre os estudantes do $7^{\circ}$ anoda E. E. Augusto Lucas, nenhum conseguiu diferenciar animais exóticos de animais nativos.

De acordo com a análise dos resultados dessa primeira questão, verificamos que além de os estudantes não conhecerem os termos "nativo" e "exótico", eles apresentam dificuldades em relação ao conceito de extinção. Grande parte dos alunos que participaram desta pesquisa acredita que o termo "exótico" significa a mesma coisa que “em extinção".Quando os estudantes foram solicitados a mencionar os animais mais conhecidos por eles, exemplificaram 42 diferentes animais. De todos os animais citados, o gato, o cachorro, o boi e a galinha apareceram com maior frequência, o que demonstra o relacionamento da resposta com fatos do cotidiano. Por serem considerados animais domésticos, é comum encontrar pelo menos uma dessas espécies nas residências dos estudantes. Segundo Moura (2004), no estado de domesticação podem estar incluídos animais de espécies nativas ou exóticas, provenientes da natureza ou do cativeiro, que passam a viver em ambiente doméstico, seja com a finalidade de consumo (alimento) ou companhia (estimação).

Nas respostas dos estudantes para a segunda questão, percebermos que, entre os animais mencionados pelos alunos, o grupo dos vertebrados obteve a quase totalidade das respostas. Dentre os vertebrados citados, os da classe Mammalia foram os mais citados. Em seguida, foram mencionadas as aves, os répteis, os anfíbios e os peixes. Uma vez que a maioria dos estudantes habita a zona rural, vive em fazendas ou tem pais que trabalham nesses locais, deduz-se que esses estudantes acabam possuindo maior convivência com os mamíferos.

Em grande parte dos questionários respondidos pelos estudantes não são citados os invertebrados. Foram citados apenas três: o carrapato, a aranha e apenas um inseto, a abelha. Esse número de citações torna-se irrelevante se comparado à grande quantidade de insetos existentes.

(RAZERA; BOCCARDO; PAULA, 2006).

As figuras. 1 e 2representam a porcentagem de citações de animais domésticos, exóticos e nativos citados pelos estudantes de $6^{\circ}$ e $7^{\circ}$ anos do ensino fundamental, durante essa primeira fase da pesquisa. 


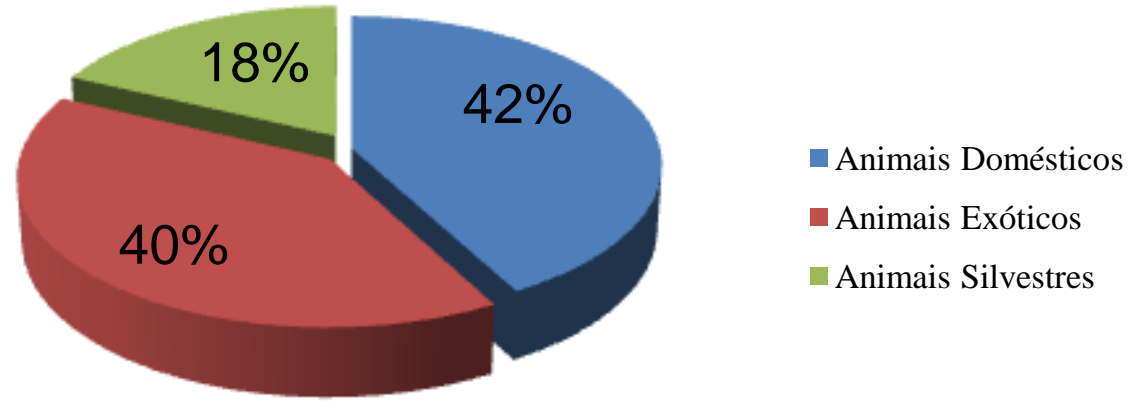

Figura 1 : Esquema representativo dos animais mais citados pelos estudantes de $7^{\circ}$ ano das Escolas Estaduais Prof. Augusto Lucas e Santa Quitéria de Esmeraldas-

MG, durante a primeira fase da pesquisa, antes da apresentação da cartilha

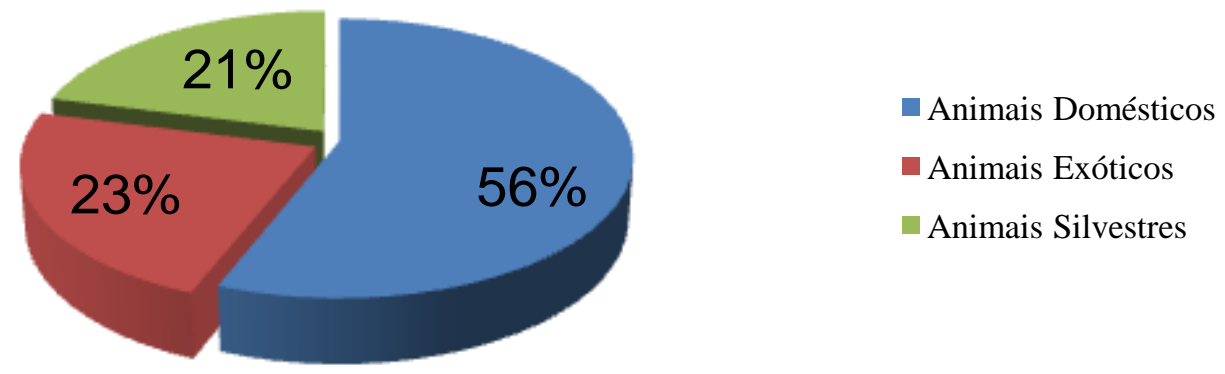

Figura 2: Esquema representativo dos animais escolhidos pelos estudasntes de $7^{\circ}$ ano das Escolas Estaduais Prof. Augusto Lucas e Santa Quitéria de Esmeraldas- MG, na primeira fase da pesquisa, antes da apresentação da cartilha

Percebe-se que nas duas situações há prevalência de animais domésticos; emsegundo lugar ficam os exóticos, e por último os silvestres. Outro aspecto que chama a atenção é a citação de animais que não fazem parte da fauna brasileira, como a zebra, o tigre, o urso, o elefante, a girafa e o leão. Isso pode ser interpretado como influência da escola, pois é comum encontrar tais exemplos e/ou ilustrações em livros didáticos (RAZERA; BOCCARDO; PAULA, 2006). A presença de animais exóticos dentre os mencionados pelos estudantes também pode ser consequência dos diversos meios de comunicação, como documentários e programas infantis; e também pode representar um reflexo das excursões, como por exemplo as realizadas ao zoológico (RAZERA; BOCCARDO; PAULA, 2006).

Segundo Oliveira (1997), as concepções dos estudantes são influenciadas por aspectos culturais, históricos, sociológicos 
e psicanalíticos. Grande parte do conhecimento sobre animais é transmitida de geração para geração, por intermédio de membros da família (pais, avós ou irmãos mais velhos, por exemplo). Alguns estudantes admitiram ter adquirido esse conhecimento na escola, com o auxílio da professora e dos livros didáticos.

De acordo com os estudantes da E. E. Santa Quitéria, as maiores fontes de informação são a escola (durante as aulas) e o livro didático. Outro importante meio de obtenção de informações é a televisão. $\mathrm{O}$ meio familiar também se apresenta como bastante relevante, já que muitos alunos escreveram que aprenderam sobre o assunto em suas casas, pois normalmente convivem com animais. Um passeio ao zoológico parece inesquecível para alguns dos alunos, que se lembram de animais como o elefante, a zebra e o gorila.

Quando analisamos as respostas oferecidas pelos estudantes da E. E. Augusto Lucas, percebemos um dado diferente: um único aluno respondeu que obteve conhecimento sobre os animais pela internet. Com relação aos demais alunos, o resultado foi semelhante ao obtido na E. E. Santa Quitéria, ou seja, a escola foi citada mais frequentemente como o meio de obtenção do conhecimento sobre os animais. A televisão também foi amplamente citada pelos estudantes como fonte da informação.
Em resposta à quarta questão ("O seu livro didático ilustra a fauna brasileira?"), os estudantes afirmaram que as duas coleções adotadas pelas escolas ilustram a fauna brasileira. Porém, a partir das respostas observa-se que os alunos indicam que a coleção adotada pela E. E. Augusto Lucas ilustra esse tema com maior ênfase.

Observamos que os alunos mantêm uma relação de afetividade com os animais. Segundo Descola (1998), atitudes de simpatia com os animais variam segundo as tradições culturais nacionais. No caso presente tal fato se confirma, uma vez que é comum encontrar em casas residenciais animais como o gato, o cachorro, pássaros, e muitas vezes animais da fauna exótica, que são cuidados pela família. Um aspecto a ressaltar é o fato de os estudantes não terem elencado animais que possuem importância religiosa, diferentemente dos achados de Razeraet al. (2006), indicados em sua pesquisa.

\section{Entrevistas com os professores}

As entrevistas com os professores tiveram o objetivo de conhecer os procedimentos adotados em sala de aula para a abordagem do tema relativo à fauna nativa, e com isso colher informações para subsidiar a produção da cartilha, objeto desta pesquisa. As entrevistas foram conduzidas na própria escola em que os professores trabalham, durante o horário cedido por eles. Todos os três docentes envolvidos mostraram-se 
interessados pelo assunto relativo à fauna nativa, e se colocaram disponíveis para relatar suas experiências e concepções.

A primeira pergunta ("Há quanto tempo você trabalha na rede estadual?") foi elaborada com o objetivo de conhecer a experiência profissional dos professores de ciências das escolas públicas de Esmeraldas. $\mathrm{O}$ resultado revelou que todos os entrevistados são contratados há mais de cinco anos pela Rede Estadual, tendo lecionado nesse período um mínimo de 18 aulas semanais no ensino fundamental.

Em resposta à segunda questão ("Em sua prática docente, como a fauna nativa é abordada em sala de aula?"), os professores declararam que o tema "fauna nativa" é pouco abordado.

A terceira questão ("Quais são os animais nativos mais citados em sala de aula?") objetivava apontar as espécies nativas focalizadas pelos professores. O mico-leãodourado foi citado por todos os três professores. Porém, não foi citado nenhum réptil ou anfíbio. Observa-se que poucos animais nativos são citados em sala de aula.

Em resposta à quarta questão ("Para você, qual a importância de se trabalhar a fauna nativa na escola?"), os professores demonstram reconhecer a importância do tema "fauna nativa", mas declaram que não o abordam em sala de aula.

A quinta questão ("Você sabe o significado do termo 'animal nativo'?") teve como objetivo verificar se os professores conheciam a definição de "animais nativos". Um dos professores apresentou a definição, os demais não responderam.

Com a sexta questão ("Em sua opinião, o livro didático consegue informar suficientemente sobre as questões de conservação da fauna nativa?") e a sétima questão ("Cite a coleção de livros de ciências adotada neste ano em sua escola.") observouse que os professores não consideram o livro adotado como um material suficiente para o desenvolvimento do tema.

A oitava questão ("A sua escola possui sala de informática equipada e disponível para os alunos?") visava definir o formato a ser proposto para o material paradidático complementar a ser produzido, produto da presente dissertação. A partir dos depoimentos das professoras, verificamos que a cartilha impressa seria a proposta mais acessível e viável.

Quanto à última questão ("Na sua opinião, quais os benefícios para o ensino de ciências na utilização de uma cartilha contendo informações e ilustrações sobre a fauna do Cerrado?"), Observou-se que os professores consideram que a cartilha, produto da presente pesquisa, é um elemento útil para complementar o livro didático. 


\section{A cartilha ilustrada com alguns animais do} Cerrado

A cartilha elaborada inclui diversas espécies de animais nativos do Cerrado, contendo informações sobre a ecologia e curiosidades sobre cada espécie. As informações presentes nesse guia foram construídas com o intuito de preencher as lacunas do livro didático, tendo em vista a ausência de materiais complementares disponíveis aos estudantes. Essa carência foi identificada na primeira fase da pesquisa, através dos resultados obtidos pelos questionários aplicados aos estudantes, pelas entrevistas com os professores, pela análise dos textos dos livros didáticos, e também por meio da revisão bibliográfica. Nessa cartilha, foram selecionados quinze vertebrados para serem abordados. Desses quinze vertebrados, foram apresentados quatro mamíferos, quatro aves, quatro répteis e três anfíbios, de forma a estabelecer as mesmas proporções em número de representantes desses grupos de animais.

\section{Apresentação da cartilha aos estudantes}

A cartilha foi apresentada a 40 estudantes de $6^{\circ}$ ano e a 53 estudantes de $7^{\circ}$ ano do ensino fundamental da E. E. Santa Quitéria. Todos esses estudantes participaram da primeira fase da pesquisa. Uma semana após a apresentação da cartilha foi aplicado um questionário. Tanto a apresentação da cartilha quanto a aplicação do questionário ocorreram no período de uma aula, cedida pelo professor.

\section{Aplicação do questionário aos estudantes, após a apresentação da cartilha}

A cartilha foi confeccionada e distribuída aos estudantes. Eles se reuniram em grupos para conhecer e discutir as informações presentes nesse material. Uma semana após a apresentação da cartilha, foi novamente aplicado um questionário, contendo três perguntas:

1. Você sabe a diferença entre animais exóticos e nativos?

2. Cite alguns animais que você mais conhece.

3. Se você tivesse que escolher um animal representante de seu país, qual você escolheria?

A primeira questão, que repete uma pergunta feita do primeiro questionário, foi novamente apresentada para verificar se os estudantes conseguiam diferenciar os termos "exótico" e "nativo" após a leitura da cartilha. O resultado foi positivo, tendo sido observada uma significativa mudança nas respostas dos alunos.Verificamos que, após a apresentação da cartilha, quando os estudantes foram solicitados a dar exemplos de animais, citaram um número maior de espécies nativas, sendo todas elas presentes na cartilha (FIG. 3). 


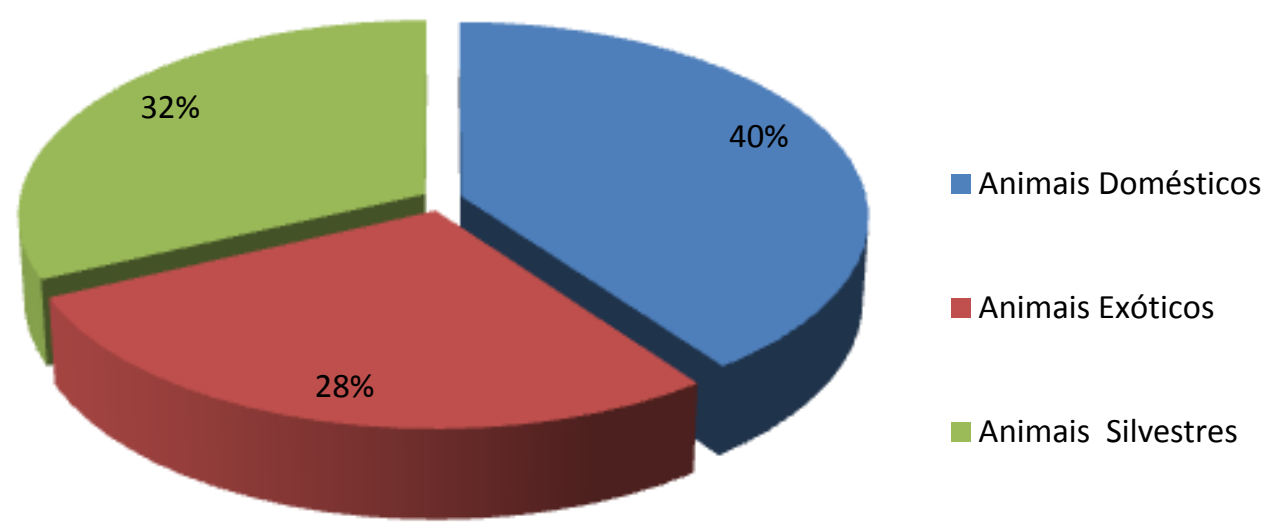

Figura 3: Esquema representativo dos animais mais citados pelos estudantes de $6^{\circ}$ e $7^{\circ}$ anos das Escolas Estaduais Prof. Augusto Lucas e Santa Quitéria, na segunda fase da pesquisa, depois da apresentação da cartilha

A coruja e as rãs são exemplos de espécies que foram citadas apenas na segunda fase da pesquisa. O tucano foi citado apenas uma vez na primeira fase e oito vezes a apresentação da cartilha. Percebemos também que os vertebrados são os animais mais conhecidos pelos estudantes e pelos professores. Ainda assim, houve aumento das citações de invertebrados nas respostas, após o contato com a cartilha.

A última questão avaliou se a cartilha proporcionou afinidade dos estudantes com algumas espécies de animais nativos, que anteriormente não tinham sido citadas, por não serem conhecidas. Algumas espécies citadas nessas respostas só estavam presentes após a utilização do material paradidático.

\section{CONCLUSÃO}

Após a apresentação da cartilha, percebe-se que houve aumento no número de citações de animais nativos nas respostas dos estudantes, assim o material exerceu influência sobre os alunos e forneceu aos estudantes informações adicionais sobre $\mathrm{o}$ assunto. Entendemos que o material despertou nos estudantes maior interesse sobre o tema, promovendo maior conhecimento e valorização da fauna regional.

Neste estudo não tivemos a intenção de desvalorizar as espécies exóticas e domésticas; o intuito foi somente o de orientar e esclarecer os estudantes quanto às diferenças entre os diversos grupos de animais existentes. É importante destacar que, em momento algum, se propõe a crítica à presença das imagens de animais exóticos nos 
manuais didáticos. Pelo contrário, sabe-se que o conhecimento não é limitado ao nosso bairro, cidade, estado ou país (SILVA, 2005), e dessa forma é plenamente justificada a apresentação aos alunos de exemplos de animais exóticos.

O que se pretendeu destacar na análise dos manuais é a maior ênfase dada aos animais exóticos e a menor ênfase dada aos animais nativos. Essa constatação se reflete na resposta dos alunos quando solicitados a elencar animais que conhecem, onde se observa uma maior concentração na citação de animais exóticos. É nesse sentido que se propõe a utilização da cartilha, que funciona como um material paradidático capaz de contrabalançar de forma mais uniforme a exposição dos alunos aos diferentes tipos de animais.

Como foi observado, depois de trabalhar com a cartilha os alunos realmente agregam ao elenco de animais conhecidos, um maior número de animais nativos. Tendo em vista a análise realizada sobre os livros didáticos adotados nas escolas públicas de Esmeraldas, onde se constata a maior presença de animais exóticos, e considerando também a influência da televisão, pois váriosprogramas são produzidos no exterior, justifica-se a confecção da cartilha,com o objetivo de expor os alunos também aos animais da fauna silvestre. Realmente fica comprovada a importância desse material paradidático para contrabalançar a exposição dos estudantes aos diferentes tipos de animais, pois as iniciativas para preservação ambiental são muito mais eficazes quando se conhece a riqueza da biodiversidade.

\section{REFERÊNCIAS}

BITTENCOURT, Circe Maria Fernandes. História, produção e memória do livro didático. Educação e pesquisa,São Paulo, v. 30, n. 3, dez. 2004.

BRASIL. Decreto n. 5.749, de 11 de abril de 2006. Regulamenta a Lei $\mathrm{n}^{\circ} 10.836$, de janeiro de 2004, que dispõe sobre o programa bolsa família que beneficia famílias em situação de pobreza. Brasília: Diário Oficial, p. 7, 13 de abr. 2006.

BRASIL. Ministério da Educação.

Parâmetros curriculares nacionais.

Brasília: MEC, 2008. Disponível em:

$<$ http://www.fnde.gov.br/home/index.jsp?arq

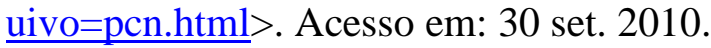

BRASIL. Ministério da Educação. Guia do livro didático - PNLD 2008: Ciências de $5^{\text {a à }}$ $8^{a}$ séries. Brasília,

2010.http://www.fnde.gov.br/home/index.jsp? arquivo=pen.html $>$. Acesso em: 30 set. 2010.

BRASIL. Ministério do Meio Ambiente. Ações prioritárias para a conservação da biodiversidade do Cerrado e Pantanal.Brasília (DF): Funatura, Fundação Biodiversitas, Universidade de Brasília, 1999.

COMPANHIA ENERGÉTICA DE MINAS GERAIS - CEMIG. Guia ilustrado de animais do cerrado de Minas Gerais. 1. ed. Belo Horizonte: Empresa das Artes, 2003.

COSTA, Lizit Alencar da et al. Avaliação das áreas verdes públicas da cidade de Manaus: situação em 1991. Caminhos de Geografia, Uberlândia, v. 6, n. 19, out. 2006. 
DESCOLA, P. Estrutura ou sentimento: a relação do animal na Amazônia. Manaus, v. 4, n. 1, p. 24-45, 1998.

GUERRA, Rafael A. T.; GUSMÃO,

Christiane R. de C. A implementação da educação ambiental numa escola de ensino fundamental - teoria vs prática.

In:ENCONTRO PARAIBANO DE EDUCAÇÃO AMBIENTAL, 2000, João Pessoa. Anais Novos Tempos. João Pessoa, 2000.

GUERRA, Rafael A. T.; GUSMÃO, Christiane R. de C. A produção de material paradidático para implementação da educação ambiental em escolas públicas de João Pessoa. 2002. Disponível em: <http://www.dse.ufpb.br/ea/Masters/Artigo_3 .pdf $>$. Acesso em: 20 jan. 2014.

INSTITUDO BRASILEIRO DE GEOGRAFIA E ESTATÍSTICA MINISTÉRIO DO PLANEJAMENTO, ORÇAMENTO E GESTÃO. Estimativa populacional 2014. Disponível em: <http//:www.ibge.gov.br>. Acesso em: 10 nov. 2014.

INSTITUTO BRASILEIRO DO MEIO AMBIENTE E DOS RECURSOS NATURAIS RENOVÁVEIS - IBAMA.

Fauna brasileira. Disponível em: <http://www.ibama.gov.br $>$. Acesso em: 10 nov. 2014.

IUCN - The World Conservation Union. 2004. A Guide to the Convention on Biological Diversity. IUCN, Gland, Switzerland. Disponível em: <http://www.iucn.org>. Acesso em: 15 mar. 2014

MOURA, R. C. G.A difícil definição de fauna exótica na legislação brasileira. In: CONGRESSO INTERNACIONAL DE DIREITO AMBIENTAL. Teses (Doutorado) 2004. Acesso em: março, 2008.

Disponívelem:

<http://www.planetaverde.org/teses/641658.pdf $>$.
OLIVEIRA, D. L. Considerações sobre o ensino de Ciências. Cadernos da Educação Básica, Porto Alegre: Mediação, 1997.

RAZERA, Júlio C. C.; BOCCARDO, Lílian B.; PEREIRA, Jussara. P. R. Percepções sobre a fauna em estudantes indígenas de uma tribo tupinambá no Brasil: um caso de etnozoologia. Revista electrónica de enseñanza de lasciencias, Ourense, vol. 5, n.3, p. 466-480, 2006.

RODRIGUES, Avelar. Esmeraldas - uma contribuição à história de Minas. Belo Horizonte: Littea, 2000.

SECRETARIA DE ESTADO DA EDUCAÇÃO DE MINAS GERAIS. Currículo Básico Comum - CBC, 52. Belo Horizonte, 2007.

SILVA, Patrícia Gomes Pinheiro da Silva; CAVASSAN, Osmar. A influência da imagem estrangeira para o estudo da botânica no ensino fundamental. Abrapec, Belo Horizonte, v. 5, n.1, 2005. 